\title{
Os confrontos em sala de aula: a que (quem) os alunos atribuem a culpa?
}

\author{
Classroom clashes: to whom (who) do the students blame?
}

Elisabeth Ramos da Silva

Doutora em Educação pela Universidade de São Paulo Docente do Programa de Mestrado em Linguística Aplicada da Universidade de Taubaté, São Paulo, SP - Brasil. lis.ramos@uol.com.br

Maria José Milharezi Abud

Doutora em Educação pela Pontifícia Universidade Católica de São Paulo Docente do Programa de Mestrado em Linguística Aplicada da Universidade de Taubaté, São Paulo, SP - Brasil. m.jose.abud@uol.com.br

Rubens Eduardo Gomes

Mestre em Linguística Aplicada pela Universidade de Taubaté Docente da Escola Estadual Escola estadual Amadeu Odorico de Souza do estado de São PauloBrasil.

professorrubens@ibest.com.br

Resumo: Este texto diz respeito à indisciplina como confronto em sala de aula, envolvendo desrespeito entre alunos e professores. A investigação objetiva examinar a visão discente acerca do que é indisciplina e dos fatores responsáveis por essas ocorrências. O motivo desta investigação é o fato de tais confrontos serem impactantes no cotidiano escolar, necessitando de reflexões que iluminem possíveis resoluções. As análises esteiam-se em teorias que sustentam a indissociabilidade entre cognição e afetividade e nas contribuições de Rego (1996), Aquino (1996), entre outros. A metodologia utilizada compreende um questionário composto de 2 perguntas dissertativas abertas para 26 alunos da $3^{a}$ série do Ensino Médio de uma escola estadual paulista. As respostas foram analisadas conforme a Análise de conteúdo de Bardin (2010). Os resultados revelam que os alunos consideram como indisciplina atos de vandalismo e desrespeito, e que a conduta do professor é responsável por tais confrontos em sala de aula.

Palavras-chave: Formação de professores. Significado e sentido da palavra. Conceito de indisciplina. Fatores da indisciplina.

Abstract: This text refers to the occurrence of indiscipline as a confrontation in the classroom, involving disrespect between students and teachers. The research aims to examine the student's view of what is indiscipline and the factors responsible for these occurrences. The reason for this investigation is the fact that such confrontations are impacting in the daily school life, needing reflections that illuminate possible resolutions. The analyzes are based on theories that support the inseparability between cognition and affectivity and on the contributions of Rego (1996), Aquino (1996), among others. The methodology used includes a questionnaire composed of 2 essay questions open to 26 high school students from a state school in São Paulo. The responses were 
analyzed according to the Bardin content Analysis (2010). The results reveal that the students regard as indiscipline acts of vandalism and disrespect, and that the conduct of the teacher is responsible for such confrontations in the classroom.

Keywords: Teachers' training. Meaning and sense of the word. Concept of indiscipline. Factors of indiscipline.

\section{Introdução}

Uma das maiores dificuldades enfrentadas pelos docentes é, sem dúvida, a indisciplina. A esse respeito, Pedro-Silva (2013) argumenta que os profissionais ligados à educação escolar não sabem como agir diante de ações indisciplinares e até violentas feitas por estudantes de diversas faixas etárias. Aquino (1996, p. 40) ressalta que "a indisciplina seria, talvez, o inimigo número um do educador atual [...]”.

Cabe aqui um breve esclarecimento acerca do usual amálgama que a escola faz entre os conceitos de indisciplina e violência. Em sentido estrito, os atos indisciplinares não deveriam compreender, em seu âmbito, atos de violência moral e física. A esse respeito, Aquino (2011), ao realizar estudo exploratório de caráter longitudinal, acerca da "tessitura" disciplinar de uma determinada instituição escolar específica, organizou as ocorrências de indisciplina em 3 categorias: infrações regimentais, atitudes impróprias e atos violentos. No entanto, segundo o autor, é preciso diferenciar as noções de incivilidade, de indisciplina e de violência.

\footnotetext{
Isso porque não é infrequente que os três vocábulos se apresentem amalgamados sob o mesmo manto semântico-pragmático de problemas disciplinares. Mais do que por uma ambiguidade linguística ou um vício formal, os três termos parecem ser frequentemente compreendidos como se portassem semelhante raiz causal, ou como se se tratasse de uma sucessão progressiva: da indisciplina à incivilidade, e desta à violência. Não há razão para sê-lo, a nosso ver. (AQUINO, 2011, p. 467).
}

É interessante observar que, embora o autor adote por definição que indisciplina consiste em “[...] um conjunto de micropráticas transgressivas dos protocolos escolares (sem contar a razoabilidade, ou não, desses), cujos efeitos se fazem sentir imediatamente na relação professor-aluno" (AQUINO, 2011, p. 468), ele admite que as ocorrências de indisciplina registradas nas escolas não se limitam ao que poderia ser considerado estritamente como tal, pois incluem atos de violência e incivilidade que ocorrem com maior ou menor intensidade no cotidiano escolar.

Neste trabalho, consideramos atos de violência como ocorrências de indisciplina porque é dessa forma que tanto alunos como professores os entendem usualmente. Segundo Rego (1996, p. 84), “o próprio conceito de indisciplina, como toda criação 
cultural, não é estático, uniforme, nem tampouco universal. Ele se relaciona com o conjunto de valores e expectativas que variam ao longo da história [...]”. Assim, o conceito de indisciplina pode assumir sentidos e significados diferenciados. Além disso, nosso objetivo era investigar o que aluno entende como indisciplina e a que fatores o aluno atribui a responsabilidade por tais atos, sejam eles simples transgressões às normas, ou cheguem a agressões e ameaças, afrontas e humilhações. Daí denominarmos esse conjunto de comportamentos indesejáveis como "confrontos" em sala de aula, sem especificar exatamente a que grupo conceitual se enquadrariam melhor.

Feitos tais esclarecimentos, esta pesquisa se justifica porque é importante investigar como o jovem vê os relacionamentos à sua volta em sua vivência diária escolar, principalmente com os seus professores, pois "a indisciplina é, em parte, produzida pelas relações interpessoais e só pode ser superada se esta dimensão for trabalhada levando-se em consideração aspectos sociais mais amplos e outros diretamente ligados à política educacional em vigência" (PEDRO-SILVA, 2013, p. 73).

Este estudo permanece no campo do signo e do pensamento, porque os adolescentes entrevistados serviram-se da linguagem para esclarecer suas concepções sobre indisciplina. Além disso, é mediante a linguagem que os pressupostos sobre a indissociabilidade entre aspectos cognitivos e afetivos constituem o crivo para a análise das respostas dos adolescentes pesquisados. Daí partirmos das ideias de Vigotski (2001) acerca das relações entre linguagem e pensamento para entendermos o fenômeno da indisciplina na voz dos adolescentes pesquisados. De fato, o comportamento tido por indisciplinado não está aquém de questões relativas a aspectos humanos, por isso é um comportamento afetivo e cognitivo simultaneamente.

Para Vygotsky (1991, p. 41), “a internalização das atividades socialmente enraizadas e historicamente desenvolvidas constitui aspecto característico da psicologia humana [...]". Assim, a conduta diferenciada de um indivíduo perante a sociedade pode ser minimamente explicada mediante o conceito de internalização de valores e experiências adquiridas ao longo do tempo. Por esse prisma, a indisciplina também pode ser entendida como produto da internalização de valores oriundos das aprendizagens compartilhadas e das vivências emocionais (peręhivanie) que atuam como guia que regula o comportamento.

Assim considerando, esclareceremos a seguir no que consiste os conceitos de internalização, consciência e vivências emocionais (perę̧ivanie), segundo Vigotski (2001), pois são tais fatores que escoram o comportamento humano observável, tornando-o adequado, ou não, a determinado contexto. Em seguida, exporemos breves considerações 
acerca do trabalho docente, já que esse item foi mencionado como um fator decisivo à disciplina na escola. Por fim, apresentaremos os procedimentos metodológicos da pesquisa, bem como a análise e nossas conclusões.

Esta pesquisa foi aprovada pela CONEP, sob o número CAAE 54852116.0.0000.5501.

\section{Aspectos teóricos que iluminaram a pesquisa}

Para entender como Vigotski (2001) compreende a formação da consciência e o processo de internalização, é preciso considerar o papel fundamental que o autor atribuía à linguagem para o desenvolvimento humano. De fato, para o autor, a palavra é o reflexo da consciência humana:

\footnotetext{
A consciência se reflete na palavra como o sol em uma gota de água. A palavra está para a consciência como o pequeno mundo está para o grande mundo, como a célula viva está para o organismo, como o átomo para o cosmo. Ela é o pequeno mundo da consciência. (VIGOTSKI, 2001, p. 486).
}

Segundo o autor, a palavra é o instrumento mais eficaz de representação da realidade, pois possui um caráter simbólico generalizante, representando conceitos. Dessa forma, é possível ao homem organizar seu pensamento e imprimir significado ao mundo. Além disso, pode igualmente expressar seu pensamento aos demais e aprender com estes o conhecimento culturalmente acumulado. Isso porque cada palavra é ao mesmo tempo um fenômeno do pensamento e da fala, sendo que a área de intersecção entre linguagem e pensamento encontra-se no significado da palavra.

Os significados das palavras (os conceitos) são aprendidos na interação do indivíduo com o seu meio. Nesse sentido, trata-se de uma herança compartilhada pelos membros de uma mesma cultura. No entanto, se cada palavra denotasse apenas o significado histórico-cultural, todos os sujeitos de uma mesma cultura teriam pensamentos semelhantes, uma vez que os conceitos apreendidos seriam exatamente os mesmos. No entanto, isso não ocorre porque o significado da palavra, além da herança cultural, abriga igualmente as impressões subjetivas, as experiências emocionais (peręhivanie), as quais se constituem segundo a história de vida de cada sujeito. São os efeitos das experiências emocionais que promovem o desenvolvimento da personalidade consciente. Em outros termos, segundo Vygotsky (1994 [1934]), a experiência emocional (perę̧ivanie) decorre da relação emocional que o indivíduo promove com os eventos de seu ambiente. Portanto, não é o acontecimento em si que determina o teor da experiência emocional, mas sim o 
modo como esse acontecimento é refratado emocionalmente pelo sujeito. Vygotsky (1994 [1934]) denomina de peręhivanie esse processo singular de refratar uma vivência.

Portanto, é no significado da palavra que os aspectos afetivos e os cognitivos se inter-relacionam intimamente, de forma indissociável. Essa inter-relação é nitidamente evidenciada por Vigotski (2001) quando ele distingue os dois componentes que constituem o significado da palavra: o "significado" propriamente dito e o "sentido". O primeiro diz respeito ao processo cultural de desenvolvimento da palavra, pois se trata de uma herança sociocultural, da qual compartilham os indivíduos de uma mesma cultura.

Por sua vez, o sentido da palavra diz respeito à acepção conferida a ela segundo as experiências de vida de cada pessoa em particular, segundo as características idiossincráticas, seus recursos cognitivos e sua visão de mundo. Assim sendo, cada sujeito se diferencia dos demais em sua maneira singular de apreender um mesmo conceito. E essa singularidade ocorre inclusive no plano ontogênico: uma criança não compreende o mundo tal como o faz um adulto. Enfim, o sentido da palavra singulariza-se sobretudo porque abriga as experiências afetivas de cada sujeito. É justamente o sentido da palavra, unido ao significado propriamente dito, que constitui um ato de pensamento e de linguagem, o qual, segundo Vigotski (2001), reflete a própria consciência.

É mediante essa apropriação singular de cada conceito, decorrente desse amálgama entre significado e sentido, que se realiza o processo de internalização e, consequentemente, da consciência. Segundo Oliveira (1992, p. 78), “o processo de internalização, isto é, de construção de um plano intrapsicológico a partir de material interpsicológico, de relações sociais, é o processo mesmo de formação da consciência". Assim, no processo de formação da consciência, a pessoa ressignifica os aspectos culturais, uma vez que "ao tomar posse do material cultural, o indivíduo o torna seu, passando a utilizá-lo como instrumento pessoal de pensamento e ação no mundo”. (OLIVEIRA 1992, p. 80)

Nessa perspectiva, a consciência se revela na dinâmica do comportamento mental que não se aliena da realidade observável do indivíduo. Assim, a consciência pode ser percebida por meio das ações praticadas, da organização objetiva do comportamento.

Tais conceitos iluminaram nossas análises acerca de como o aluno compreende e interpreta os confrontos em sala de aula, os quais, grosso modo, são denominados de indisciplina, ainda que comportem atos de violência, uma vez que muitas atitudes configuram-se como verdadeiras agressões físicas ou morais. Rego (1996) identifica o aluno indisciplinado como aquele que: 
[...] não tem limites, que não respeita a opinião e sentimentos alheios, que apresenta dificuldades em entender o ponto de vista do outro e de se autogovernar [...], que não consegue compartilhar, dialogar e conviver de modo cooperativo com seus pares. (REGO, 1996, p. 87).

Ainda segunda a autora, o comportamento considerado como indisciplinado não decorre apenas de determinados fatores que atuam de forma isolada no aluno, tal como a influência da televisão, a falta de autoridade do professor ou a violência do mundo contemporâneo. Trata-se da conjuminância de várias influências que incidem na criança e no jovem ao longo de seu desenvolvimento.

Um dos fatores citados pela autora é a questão da autoridade docente. E um dos quesitos necessários para que a autoridade do professor seja legitimada é o domínio teórico dos conteúdos da disciplina que leciona. Porém, não basta revelar exímio conhecimento teórico. Aquino (1999) considera que a autoridade do professor depende não só do domínio teórico dos conteúdos, mas também do domínio metodológico, da mestria no exercício de sua função docente.

$\mathrm{Na}$ perspectiva de Davis e Luna (1991), a autoridade do professor deve ser exercitada para orientar e intervir, quando for necessário. A mestria com que o docente conduz o aluno deve ser capaz de suscitar "uma obediência voluntária" (DAVIS; LUNA, 1991, p. 68), bem como deve promover a "convergência de interesses" (p. 68), e estar a serviço “da formação de um cidadão lúcido" (p. 68), por isso precisa estar "baseada em respeito mútuo" (p. 68).

Cremos que tais esclarecimentos teóricos serão úteis para a compreensão de nossas análises. Nesta pesquisa, consideramos a palavra em sua constituição de significado e sentido; pois, como afirmou Vigotski (2001), nela se reflete o processo consciente de apreensão de mundo. Daí termos optado, como procedimento metodológico, pela Análise de Conteúdo segundo Bardin (2010).

\section{A pesquisa}

Os sujeitos dessa pesquisa compreendem 26 alunos (entre 16 e 17 anos de idade), da $3^{a}$ série do Ensino Médio de uma escola estadual paulista. Nosso objetivo foi investigar o que aluno entende como indisciplina e a que fatores atribui a responsabilidade pelos confrontos que ocorrem entre professor e aluno em sala de aula. 
Para alcançarmos tais dados, pedimos a nossos sujeitos de pesquisa que respondessem por escrito às seguintes perguntas: "Em sua opinião, o que é indisciplina?" e "Se você fosse professor (a), o que você faria para manter a disciplina em suas aulas?"

Para analisarmos as respostas de nossos sujeitos de pesquisa, empregamos a análise de conteúdo na perspectiva de Bardin (2010). Como método de investigação, a análise de conteúdo consiste em um conjunto de técnicas específicas de análise de comunicações (BARDIN, 2010) que, ao proporcionar uma descrição analítica das mensagens, contribui para que o pesquisador reconheça e interprete as unidades de significação concernentes ao conteúdo dos enunciados. Esse tratamento dispensado ao material do corpus permite ainda que o pesquisador efetive inferências específicas por intermédio da dedução de temas recorrentes ou pressupostos implícitos ou explícitos contidos no material de análise.

De modo específico, ao enfatizar o papel da inferência, Bardin (2010, p. 44) sintetiza o terreno, o funcionamento e o objetivo da análise de conteúdo, esclarecendo que esta pode ser definida como "um conjunto de técnicas de análise das comunicações", sendo que, em tais técnicas, visa-se obter, por meio de procedimentos sistemáticos de descrição do conteúdo dos enunciados, "indicadores (quantitativos ou não) que permitam a inferência de conhecimentos relativos às condições de produção [...] destas mensagens".

Em nossa pesquisa, a leitura atenta do material de análise consoante as técnicas de análise de conteúdo de Bardin (2010) propiciou alcançar a interpretação mais profunda dos dados, assim como possibilitou a realização de inferências pelo cruzamento das respostas, atendo-se ao contexto da realidade concreta em que elas foram produzidas. Para isso, procuramos obter nas respostas tanto os sentidos explícitos quanto os implícitos, o que nos proporcionou condições para examinar as diferenças de significação entre os conteúdos dos enunciados, como também as nuanças de semelhança que eles apresentavam.

Com tal procedimento, nomeamos os temas recorrentes que emergiram das respostas dos sujeitos da pesquisa. Tais temas foram agrupados em categorias sob um título genérico. A frequência $(\mathrm{F})$ e o percentual $(\mathrm{P})$ dizem respeito ao número de vezes que a categoria é mencionada nas respostas dadas por eles, e não ao número de participantes da pesquisa.

Dessa forma foi possível estabelecer quatro categorias para a primeira pergunta e sete para a segunda. A frequência $(\mathrm{F})$ e o percentual $(\mathrm{P})$ dizem respeito ao número de vezes que a categoria é mencionada nas respostas dadas por eles, e não ao número de participantes da pesquisa.

Abaixo, apresentamos os quadros resultantes das análises iniciais. 
Quadro 1 - Em sua opinião, o que é indisciplina?

\begin{tabular}{|c|c|}
\hline Categorias & Exemplos \\
\hline $\begin{array}{l}\text { Falta de } \\
\text { respeito e/ou } \\
\text { de limite com } \\
\text { o próximo } \\
\text { F- } 15 \\
\text { P }-57,6 \%\end{array}$ & $\begin{array}{l}\text { "Indisciplina é não respeitar as pessoas ao seu redor, normalmente por puro capricho. } \\
\text { Querer sempre ser o centro das atenções e fazer as pessoas de cobaias para suas } \\
\text { palhaçadas." } \\
\text { "[...] muitos deles não tem respeito com os colegas de sala de aula, fazem bagunça, não } \\
\text { respeita professores e diretores e adoram causar tumulto." } \\
\text { "Indisciplina é falta de respeito tanto dentro da escola como fora [...] não aceitar ouvir uma } \\
\text { ordem de outra pessoa com um cargo superior [...]" } \\
\text { "Falta de respeito com o próximo, mas não digo falta de respeito somente com as } \\
\text { autoridades (professores, inspetores, coordenadores) digo falta de respeito com o ser } \\
\text { humano [...]" } \\
\text { "Indisciplina é algo que gera desrespeito ao próximo independente de idade, é falta com } \\
\text { respeito com alguma autoridade ou até mesmo com algum colega." } \\
\text { "Minha definição para disciplina é falta de ordem e respeito de um grupo ou de um } \\
\text { indivíduo." } \\
\text { "Indisciplina é você não ter respeito por nada [...]" } \\
\text { "[...] faltar com respeito aos seus professores, xingar e até mesmo agredir, [...] é vir para a } \\
\text { escola e achar que pode fazer o que bem entende sem se preocupar com as consequências } \\
\text { que podem acabar causando." } \\
\text { "[...] e insultar os outros [...]." }\end{array}$ \\
\hline $\begin{array}{l}\text { Conduta } \\
\text { inadequada } \\
\text { aluno } \\
\text { F-10 } \\
\text { P-38,4\% }\end{array}$ & $\begin{array}{l}\text { "Em minha opinião, indisciplina é quando uma pessoa, ou um grupo de pessoas não se } \\
\text { comportam na devida maneira em um determinado local, assim causando algum tipo de } \\
\text { discórdia." } \\
\text { "Para mim, indisciplina é [...] se portar indevidamente diante o outro, [...] cortar uma } \\
\text { pessoa enquanto ela fala, é desobedecer, desacatar, agir com descaso com outra pessoa } \\
{[\ldots] "} \\
\text { "É não prestar atenção nos estudos, [...] na aula e atrapalhar aqueles que querem aprender, } \\
\text { é vir para a escola e achar que pode fazer o que bem entende sem se preocupar com as } \\
\text { consequências que podem acabar causando." } \\
\text { "Em minha opinião indisciplina é quando [...] fazem algo de livre e espontânea vontade } \\
\text { sem que seja dito ou de seu direito. Fazem as coisas que se dão na telha sem ligar para a } \\
\text { opinião dos outros." }\end{array}$ \\
\hline $\begin{array}{l}\text { Desobediência } \\
\text { às regras } \\
\mathrm{F}-10 \\
\mathrm{P}-38,4 \%\end{array}$ & $\begin{array}{l}\text { "Indisciplina é, na minha opinião, quando um determinado aluno, ou um grupo de alunos } \\
\text { desrespeitam regras impostas por professores ou qualquer outra autoridade de uma escola } \\
{[\ldots . .] "} \\
\text { "[...] falta de respeito com regras e normas de uma sociedade." } \\
\text { "[...] quebrar regras e insultar os outros." } \\
\text { "Indisciplina é quando uma pessoa, no caso um aluno, falta com a ordem, desobedecendo } \\
\text { regras, leis e normas. [...]" } \\
\text { "Na minha opinião, indisciplina é quando alguém desobedece as regras [...]" }\end{array}$ \\
\hline $\begin{array}{l}\text { Atitudes } \\
\text { docentes } \\
\text { negativas }\end{array}$ & $\begin{array}{l}\text { "[...] os professores precisam modificar os aspectos negativos que incomodam os alunos } \\
\text { para que assim tornem suas aulas um lugar agradável [...]" }\end{array}$ \\
\hline
\end{tabular}

Fonte: elaboração própria

Ao serem questionados sobre a indisciplina, os alunos $(57,6 \%)$ reportaram-se principalmente às suas experiências em sala de aula. De fato, segundo Amado (2001, p. 417), "A indisciplina implica, sempre, a contravenção de princípios, regulamentos, contratos e ordens, em clara discordância com os objetivos do grupo ou instituição e provocando situações de perturbação das relações sociais no seu interior". No entanto, ao definirem como indisciplina: "Falta de respeito com o próximo, mas não digo falta de 
respeito somente com as autoridades (professores, inspetores, coordenadores) digo falta de respeito com o ser humano [...]", os alunos aludem aos confrontos desrespeitosos que extrapolam acordos relativos a regras, pois ferem a dignidade do próximo. Aqui, não se trata de uma atitude rebelde diante de uma norma imposta, ou de uma transgressão a regras autoritárias que não fazem sentido ao jovem, mas sim de uma agressão à pessoa (ao ser humano), sem justificativa. A indisciplina assume sentidos mais abrangentes, pois é vista por esses sujeitos como condutas que se estendem muito além dos muros da escola, não dependendo das regras acordadas entre alunos e professores: "Fazem as coisas que se dão na telha sem ligar para a opinião dos outros." Trata-se de uma conduta de vida, de uma "falha de caráter", de um agir no mundo ignorando os limites que preservam o bem-estar do próximo. Nota-se que há componentes de violência que perpassam esses atos considerados como indisciplina.

Alguns sujeitos (38,4\%) entendem a indisciplina como desrespeito a regras. Nesse caso, o sentido de indisciplina encontra-se em conformidade com a opinião dos especialistas. Apenas um aluno atribuiu a indisciplina às atitudes docentes: "[...] os professores precisam modificar os aspectos negativos que incomodam os alunos para que assim tornem suas aulas um lugar agradável [...]". Neste caso, fica evidente que esse sujeito considera que a responsabilidade da indisciplina cabe à falta de maestria do professor. Essa resposta correlaciona-se com o que os sujeitos expuseram na próxima questão.

Quadro 2 - Se você fosse professor(a), o que você faria para manter a disciplina em suas aulas?

\begin{tabular}{|c|c|}
\hline Categorias & Exemplos \\
\hline $\begin{array}{l}\text { Tratamento } \\
\text { dispensado ao } \\
\text { aluno e ao } \\
\text { ensino } \\
\mathrm{F}-18 \\
\mathrm{P}-69,2 \%\end{array}$ & $\begin{array}{l}\text { "Eu começaria a dar o melhor de mim, me esforçaria cada vez mais e [...] ensinaria aos } \\
\text { alunos aquilo que eu aprendi, e tentando ser uma ótima professora." } \\
\text { "[...] iria atraí-los com uma nova forma de ensinar, de uma forma que não faria da aula uma } \\
\text { coisa que eles se sentissem obrigados a fazer aquilo, fazendo a aula uma coisa dinâmica que } \\
\text { todos tivessem o interesse de participar." } \\
\text { "[...] falaria de uma forma que fosse próxima de suas realidades, mas principalmente, } \\
\text { demonstraria amor por aquilo que faço." } \\
\text { "Bom seria paciente, tentaria deixar minha aula mais divertida para trazer atenção dos } \\
\text { alunos." } \\
\text { "Daria liberdade de expressão aos alunos, traria propostas de aulas diferenciadas, não } \\
\text { seguiria a grade curricular, pois ela limita o professor e deixa as aulas corridas." } \\
\text { "Se eu fosse professor eu ia fazer aulas mais divertidas com brincadeiras, com apresentação } \\
\text { de temas mais legais, conversaria com a sala sobre o dia a dia do país. Não seria aquele } \\
\text { professor que só passa apostila, mas seria um professor que ia conversar mais com as salas, } \\
\text { e durante essa conversa eu ia passar a matéria." } \\
\text { "Pediria a opinião dos alunos, faria atividades diferenciadas, debateria com os alunos sobre } \\
\text { a escola, e como mudá-la, deixando o aluno, por exemplo, no TCC escolher seu próprio } \\
\text { tema. Basicamente não deixaria a aula ficar pesada, uma aula que como aluno gostaria." } \\
\text { "[...] sem deixar de passar as matérias e passando atividades que os alunos se interessem e } \\
\text { queiram aprender passando de um jeito que eles gostem." }\end{array}$ \\
\hline Autoridade em & "Colocaria respeito, os alunos poderiam brincar, mas sempre deixando de lado as \\
\hline
\end{tabular}




\begin{tabular}{|c|c|}
\hline $\begin{array}{l}\text { sala de aula } \\
F-12 \\
P-46,1 \%\end{array}$ & $\begin{array}{l}\text { brincadeiras para poder aprender, mas pediria para eles se comportarem [...]" } \\
\text { "[...] ter autoridade em sala de aula [...]" } \\
\text { "Primeiramente tiraria pontos daqueles que ficassem no celular e sem o material, explicaria } \\
\text { uma vez só e ficaria observando a atitude dos alunos, pois os professores que se matam } \\
\text { para que sejam ouvidos levam o nome de bobo, trouxa, já o que é curto e grosso desperta } \\
\text { o interesse pela lição e fica mais fácil conquistar a nota." } \\
\text { "Eu de certa forma iria impor meus direitos como professor, mas sem abusar dos meus } \\
\text { direitos [...]" } \\
\text { "É uma questão de "respeito", se eu quero respeito eu tenho que respeitar }[. . .] " \\
\text { " [...] tentaria ter voz para que prestassem atenção em mim [...]" } \\
\text { "Além de tudo, mostraria que os alunos teriam que me respeitar, corrigiria assim que } \\
\text { preciso, mostraria autoridade }[. . .] " \\
\text { "Se eu fosse professor eu tentaria impor respeito }[\ldots . .] "\end{array}$ \\
\hline $\begin{array}{l}\text { Características } \\
\text { pessoais } \\
\mathrm{F}-11 \\
\mathrm{P}-42,3 \%\end{array}$ & 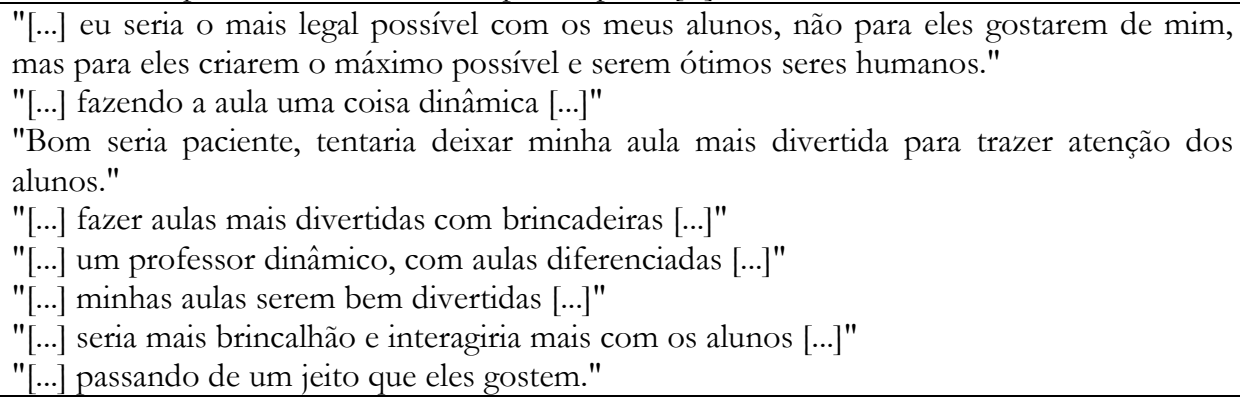 \\
\hline $\begin{array}{l}\text { Respeito pelos } \\
\text { alunos } \\
\text { F }-06 \\
P-23 \%\end{array}$ & $\begin{array}{l}\text { "Antes de mais nada, eu iria respeitar os alunos, porque respeito sempre tem que vir em } \\
\text { primeiro lugar [...]." } \\
\text { "[...] pediria para eles [...] e me respeitarem como eu vou respeitar eles." } \\
\text { "[...] sabendo respeitar o aluno como diz o ditado 'respeita para ser respeitado'." } \\
\text { "[...] eu respeitaria a dificuldade, o jeito e a vida de cada um [...]" } \\
\text { " [...] tentaria dar atenção a todos, tentaria ter voz para que prestassem atenção em mim, } \\
\text { sem gritar nem ser grossa, claro." }\end{array}$ \\
\hline $\begin{array}{l}\text { Confiança dos } \\
\text { alunos } \\
\text { F }-04 \\
P-15,3 \%\end{array}$ & $\begin{array}{l}\text { "Primeiro comunicação com o aluno é a base de tudo, e com isso o aluno venha a ter } \\
\text { confiança em você, e em consequência vem a disciplina, vem o respeito." } \\
\text { "Tentaria conquistar a confiança dos alunos [...]" } \\
\text { "[...] seria também amiga dos meus alunos, pois para mim isso é essencial." } \\
\text { "Eu tentaria virar amigo dos alunos [...]" }\end{array}$ \\
\hline $\begin{array}{l}\text { Atualização } \\
\text { constante } \\
\text { F - } 01\end{array}$ & $\begin{array}{l}\text { "Seria mais dinâmica e atualizada, [...] cada época haverá algo diferente para prender a } \\
\text { atenção." }\end{array}$ \\
\hline $\begin{array}{l}\text { Criação de } \\
\text { regras }\end{array}$ & "[...] conversaria com eles para criar algumas regras para \\
\hline
\end{tabular}

Fonte: elaboração própria

Vemos que, neste caso, quando são indagados sobre qual deveria ser a atuação do professor para manter a disciplina, os sujeitos não se referiram à criação de regras ou à discussão sobre elas, mas a características pejorativas dos docentes, as quais, segundo eles, quando sanadas, melhorariam a qualidade da disciplina. Apenas um aluno sugeriu a criação de regras. É interessante observar o contrassenso entre as duas questões: se a indisciplina é definida como a falta de respeito do aluno às pessoas de modo geral, como pode ser minimizada se apenas a pessoa do professor respeitar o aluno, ou se ele for divertido e simpático: "É uma questão de respeito, se eu quero respeito eu tenho que respeitar [...]" 
(grifo nosso). Parece que o desrespeito nunca parte do aluno, e sim da conduta docente, ou, quando muito, da falta de autoridade do professor.

De fato, todas as categorias revelam que, se o professor alterasse a forma de agir, a disciplina seria mantida. Assim sendo, o aluno é isento de qualquer responsabilidade, pois esta é transferida unicamente à incapacidade do professor em: respeitar o aluno, impor sua autoridade, oferecer aulas interessantes e divertidas, lutar por seus direitos e até em manter a vOZ, como sugeriu um dos sujeitos: “[...] tentaria ter vOz para que prestassem atenção em $\operatorname{mim}[\ldots]^{\prime \prime}$.

Talvez tais observações acerca do sentido conferido à disciplina e às suas causas iluminem alguns motivos da crescente violência contra o professor. $\mathrm{O}$ aluno se sente como aquele que simplesmente reage à conduta do professor, por isso não tem obrigação de respeitá-lo se não gostar dele. O fato de ser professor não mais causa a reverência que um mestre mereceria pelo simples fato de ser aquele que vai conduzir o aluno ao conhecimento. Parece que o professor precisa "merecer" respeito e, para tanto, precisa subordinar-se à vontade dos alunos: "Daria liberdade de expressão aos alunos, traria propostas de aulas diferenciadas, não seguiria a grade curricular, pois ela limita o professor e deixa as aulas corridas." (grifo nosso). Ou seja: cabe ao professor satisfazer o aluno, ainda que tenha que ignorar os conteúdos propostos na grade curricular e ser infiel ao que se propôs realizar.

Ao se imaginar professor, o sujeito da pesquisa transfere a culpa para si, diversamente do que ocorreu na primeira questão. Nesta, o aluno referiu-se à indisciplina como uma característica observada nos outros, sem incluir-se nos comentários: "Em minha opinião, indisciplina é quando uma pessoa, ou um grupo de pessoas não se comportam na devida maneira em um determinado local, assim causando algum tipo de discórdia." (grifo nosso). Nenhum aluno utilizou o pronome ou o verbo na primeira pessoa. Nenhum aluno confessou-se indisciplinado, já que a indisciplina é vista como uma questão ética por envolver condutas desrespeitosas com os demais.

\section{Conclusões}

Muito ainda poderia ser dito, mas parece que todas as observações, em maior ou menor intensidade, convergiriam para esse descrédito em relação à importância do papel de um professor, que deveria merecer respeito principalmente pelo lugar que ocupa na formação de um indivíduo, e não por ser simpático e divertido. É claro que alguns professores são mais estimados que outros, mas respeito e disciplina deveriam ser 
condições imprescindíveis em qualquer relação humana, sobretudo quando se trata da relação entre mestre e discípulo, em que a autoridade do professor tem que ser preservada.

Ao lermos as respostas, resta a impressão de que o professor precisa submeter-se sempre ao crivo do aluno para poder realizar o seu trabalho. A questão é que os critérios que norteiam a avalição dos alunos em relação ao professor não são claros, e muitas vezes sequer são adequados. De fato, parece que não se trata de realizar a tarefa docente com esmero e maestria, mas sim de "agradar ao aluno" naquilo que este considera como dinâmico e divertido. Nesse sentido, por serem critérios diferenciados e por vezes idiossincráticos, torna-se quase impossível que um professor agrade a todos. E, caso não agrade a alguns, estes considerarão suas condutas indisciplinadas como legítimas, já que a "culpa" dos confrontos em sala de aula é do professor que não conseguiu conquistar prontamente seus alunos. Em síntese, em alusão às ideias de Vigotski (2001), os sentidos das palavras indisciplina e professor vêm contemporaneamente ganhado tons singulares: a palavra indisciplina muitas vezes associa-se à violência, e a palavra professor despiu-se da reverência que lhe era inerente e ganhou sentidos pejorativos. Por isso, a atitude de perplexidade que muitos educadores hoje manifestam terá que ceder lugar a uma reflexão honesta de como resgatar a importância do professor como aquele que promove a educação dos cidadãos deste país.

\section{Referências}

AMADO, João da Silva. Interação pedagógica e indisciplina na aula. Porto: Edições ASA, 2001. Coleção: Perspectivas Actuais/Educação.

AQUINO, Julio Groppa. Da (contra)normatividade do cotidiano escolar: problematizando discursos sobre a indisciplina discente. Cadernos de Pesquisa, São Paulo, v. 41, n. 143, p. 456484, maio/ago. 2011. Disponível em:

<http://www.scielo.br/pdf/cp/v41n143/a07v41n143.pdf>. Acesso em: 22 jul. 2015.

AQUINO, Julio Groppa. Autoridade docente, autonomia discente: uma equação possível e necessária. In: AQUINO, Julio Groppa (Org.). Autoridade e autonomia na escola: alternativas teóricas e práticas. São Paulo: Summus, 1999. p. 131-153.

AQUINO, Julio Groppa. A desordem na relação professor-aluno: indisciplina, moralidade e conhecimento. In: AQUINO, Julio Groppa (Org.). Indisciplina na escola: alternativas teóricas e práticas. 16. ed. São Paulo: Summus, 1996. p. 39-55.

BARDIN, Laurence. Análise de conteúdo. Tradução de Luís Antero Reto e Augusto Pinheiro. 4. ed. Lisboa: Edições 70, 2010. 
DAVIS, Cláudia; LUNA, Sérgio. A questão da autoridade na educação. Caderno de Pesquisa, São Paulo: Fundação Carlos Chagas, n. 76, p. 65-70, fev. 1991. Disponível em: $<$ http://publicacoes.fcc.org.br/ojs/index.php/cp/article/view/1056/1064>. Acesso em: 2 jun. 2016.

OLIVEIRA, Marta Kohl de. O problema da afetividade em Vygotsky. In: LA TAILLE, Yves de; OLIVEIRA, Marta Kohl de; DANTAS, Heloysa. Piaget, Vygotsky, Wallon: teorias psicogenéticas em discussão. São Paulo: Summus, 1992. p. 75-84.

PEDRO-SILVA, Nelson. Ética, (in)disciplina e relação professor-aluno. In: LA TAILLE, Yves de; JUSTO, José Sterza; PEDRO-SILVA, Nelson. Indisciplina, disciplina: ética, moral e ação do professor. 5. ed. Porto Alegre: Mediação, 2013. p. 69-120.

REGO, Teresa Cristina R. A indisciplina e o processo educativo: uma análise na perspectiva vygotskiana. In: AQUINO, Julio Groppa (Org.). Indisciplina na escola: alternativas teóricas e práticas. 16. ed. São Paulo: Summus, 1996. p. 83-101. VIGOTSKI, Lev Semenovich. A construção do pensamento e da linguagem. Tradução Paulo Bezerra. São Paulo: Martins Fontes, 2001.

VYGOTSKY, Lev Semenovich. The problem of the environment. In: VAN DER VEER, René; VALSINER, Jaan (Ed.). The Vygotsky Reader. Oxford: Blackwell Publisher, 1994. p. 338-354. [1934. This was the fourth lecture published in Vygotsky, L. S. 1935: Foundations of Paedology (p. 58-78). Leningrad: Izdanie Instituta. The chapter heading is our invention. In reality, the chapters (or rather, lectures) were simply numbered]. Disponivel em: $<$ http://www.marxists.org/archive/vygotsky/ works/1934/ environment.htm>. Acesso em: 13 fev. 2011.

VYGOTSKY, Lev Semenovich. A formação social da mente. 4. ed. São Paulo: Martins Fontes, 1991. Disponível em: <http://www.egov.ufsc.br/portal/sites/default/ files/vygotsky-aformac3a7c3a3o-social-da-mente.pdf>. Acesso em: 4 jun. 2015.

VYGOTSKY, Lev Semenovich. Pensamento e linguagem. Ridendo Castigat Mores, 2001. Disponível em: <http://www.someeducacional.com.br/palestras/Vygotsky.pdf>. Acesso em: 4 jun. 2015.

Recebido em: 03 abr. 2019 / Aprovado em: 25 jun. 2019

\section{Cite como}

SILVA, Elisabeth Ramos da; MLHAREZI ABUD, Maria José; GOMES, Rubens Eduardo. Os confrontos em sala de aula: a que (quem) os alunos atribuem a culpa? Dialogia, São Paulo, n. 32, p. 25-37, maio/ago. 2019. Disponível em: https://doi.org/10.5585/Dialogia.n32.13419. 